\title{
A INFORMAÇÃO EM PROFISSÕES EM SEU QUINTO ANO DE EXISTÊNCIA
}

A revista Informação@Profissões apresenta o seu quinto volume trazendo relevantes contribuições para a comunidade técnico-científica. Esta edição é composta por duas seções, são elas: "Comunicações", com seis estudos e "Relatos de Experiência", contendo dois relatos.

A seção "Comunicações" inicia-se com "Pedagogia, Arquitetura e Biblioteconomia: processos pedagógicos para reestruturar uma biblioteca escolar" dos autores Rovilson José da Silva, Teba Silva Yllana, Felipe Martins Menck e Giovana Takahashi de Oliveira. Nesta comunicação discute-se que as bibliotecas escolares em geral ainda não conseguiram propiciar, aos seus leitores, um espaço que possam sentir-se acolhidos física, psicológica e culturalmente, e a biblioteca do Instituto Estadual de Educação de Londrina (IEEL) não é uma exceção. Com o objetivo de disseminar as interferências realizadas na biblioteca do IEEL pela equipe do Projeto de extensão "Formação do Mediador de leitura em escola pública” no período de 2012 a 2015.

Prossegue com a comunicação intitulada "Interferência da autoimagem do bibliotecário escolar na mediação da informação" dos autores João Arlindo Santos Neto e Tatiane de Fatima Farina. Neste estudo analisa-se a autoimagem do bibliotecário escolar das escolas particulares e públicas de Londrina. Discute os termos autoimagem, imagem e autoestima no contexto do profissional da informação. Com o objetivo de investigar se a autoimagem dos bibliotecários escolares interfere na mediação da informação e verifica como essa interferência ocorre nos processos e nas práticas informacionais.

Outro estudo em questão refere-se a "Biblioterapia no âmbito hospitalar" das autoras Sueli Bortolin e Sandra da Silva. Nesta comunicação reflete-se sobre a importância que a leitura tem para pessoas hospitalizadas. A leitura está presente na sociedade há 
milhares de anos, a junção entre leitura e terapia denominada biblioterapia, ainda é uma técnica pouco utilizada por profissionais da Saúde e pouco pesquisada por profissionais da informação. Com o objetivo de investigar, na perspectiva dos integrantes do projeto Sensibilizarte, como a biblioterapia pode ajudar pessoas que estão hospitalizadas.

Em seguida, destaca-se a comunicação "Ações Intergeracionais: a ressignificação do idoso nas instituições informacionais" da autora Simone Borges Paiva. Neste estudo discute-se uma nova etapa para as relações que mantemos com os idosos e deles com as mais diferentes faixas etárias. Com o objetivo de apresentar iniciativas que tenham nas relações intergeracionais seu mote desencadeador, com atenção especial, embora não exclusiva, àquelas ligadas à área da Biblioteconomia.

Também faz parte dos temas discutidos nesta seção "Reflexões sobre o livro digital: circulação, preservação e fixação" do autor Wesley Augusto Nogueira. Nesta comunicação propõe-se discutir a conceituação de livro e apresentar questões referentes à introdução do livro digital e os aspectos concernentes ao seu acesso, circulação e preservação. Com o objetivo de conduzir à reflexão sobre o lugar do livro na sociedade da informação e de que maneira seu uso pode potencializar seus aspectos negativos e positivos, desde o livre acesso ao conhecimento até a cisão ainda maior entre informacionalmente integrados e excluídos.

Ainda na seção de Comunicações apresenta-se "Preservação da informação: gerenciar para possibilitar o acesso" da autora Luana de Almeida Nascimento. Nesta comunicação destacam-se as reflexões acerca da preservação da informação sob a ótica dos autores da Arquivologia e da Ciência da Informação. Com o objetivo de apresentar uma revisão teórico-conceitual da preservação da informação com base nos teóricos da Preservation of Information Specialization da Universidade de Michigan apontados por Silva (2008). 
A seção "Relatos de Experiência" discute-se sobre "Ação cultural para reinvenção das práticas em bibliotecas: criação de outros meios e outros fins: as contribuições do Coletivo Estopô Balaio" do autor Marcos Paulo de Passos. Neste relato enfatiza-se que a Ação Cultural é campo conceitual e de prática experimental do campo das Artes, presente, também, nas práticas profissionais de bibliotecários em bibliotecas públicas. Com o objetivo de assinalar a importância do diálogo de diferentes profissionais, dentro e fora das bibliotecas, que possam conferir articulação e autonomia expressiva para grupos culturais locais, redimensionar práticas e possibilidades de experimentação diversa nos dispositivos culturais da cidade.

Encerra-se esta seção com o relato "A música como fonte representativa de informação: o caso da Fonoteca Satyro de Mello no Centur/ FCPTN" dos autores Jetur Lima de Castro e Alessandra Nunes de Oliveira. Neste relato considera-se a música como fonte interpretativa de informação. Com o objetivo de apresentar a importância da música com aspecto representativo na Fonoteca Satyro de Mello como processo social e informacional.

Espera-se que a publicação desta edição inspire e valorize o compartilhamento de experiências, por meio desse veículo de comunicação, com as demais Instituições de pesquisa, em nível técnicocientífico, brasileiras.

Convido a todos à leitura!

\section{Professora Brígida Cervantes}

Departamento de Ciência da Informação Centro de Educação, Comunicação e Artes Universidade Estadual de Londrina 